\title{
State of the art in rotator cuff repair
}

\author{
Pietro Randelli $\cdot$ Klaus Bak · Giuseppe Milano
}

Received: 6 January 2015 / Accepted: 13 January 2015 / Published online: 29 January 2015

(C) European Society of Sports Traumatology, Knee Surgery, Arthroscopy (ESSKA) 2015

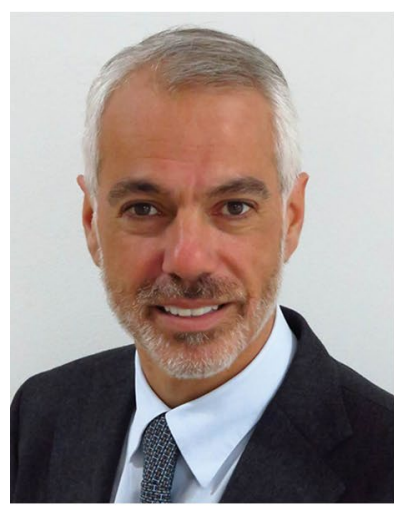

Pietro Randelli

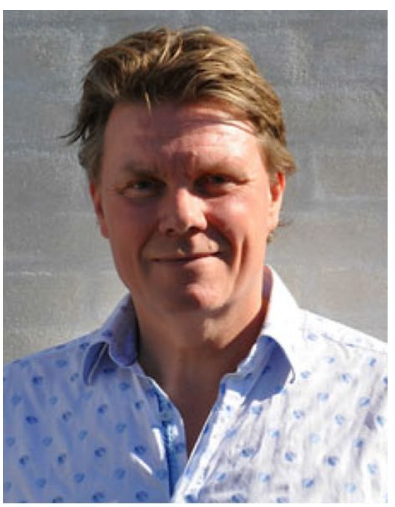

Klaus Bak

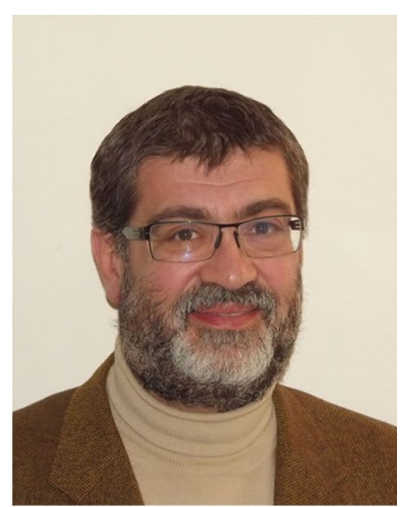

Giuseppe Milano
The very first description of a torn rotator cuff appeared in 1788, when Alexander Monro depicted a tear in the supraspinatus and infraspinatus in his book A Description of All the Bursal Mucosae of the Human Body. About 100 years later, Hüter was the first to re-attach the torn cuff tendons to a humeral diaphysis after a humeral head resection. Finally, in 1906, Georg Clemens Von Perthes reported

\section{P. Randelli $(\bowtie)$}

Dipartimento di Scienze Biomediche per la Salute, Università degli Studi di Milano, Via Mangiagalli 31, 20133 Milan, Italy e-mail: pietro.randelli@unimi.it

\section{P. Randelli}

IRCCS Policlinico San Donato, Via Morandi 30, 20097 San

Donato Milanese, Milan, Italy

\section{K. Bak}

Teres Hospitalet Parken, Copenhagen, Denmark

\section{G. Milano}

Division of Orthopaedic Surgery, Catholic University, "A.

Gemelli” University Hospital, Largo A. Gemelli 8, Rome, Italy about a series of three rotator cuff repairs (RCR) in which suture anchors were used for the first time. Later, in 1911, it was Ernest Amory Codman who first described the surgical technique for repairing supraspinatus tendon lesions in the USA.

After these pioneers, several famous surgeons developed surgical repair strategies, with open transosseous repair becoming the standard until the development of the arthroscopic techniques in the last decade of the twentieth century [16].

Alongside the development of surgical strategies, radiological investigations improved with a view to providing a greater understanding of cuff pathologies and enabling precise indications. Not only MRI but also ultrasound and radiographs, as underlined by Michener et al. [15] and Cho et al. [6], should be in the arsenal of the modern shoulder surgeon. Due to repair strength problems related to the suturing of poor quality tendon tissue [21], more recent radiological investigations have concentrated on tendon characteristics, to enable prognostic evaluations of tissue healing and the reparability of the cuff. The paper by 
Tudisco [20], on Real-time sonoelastography, following this editorial, focuses on this important role of radiology when applied to this surgery.

When it comes to the usefulness of MRI when studying cuff tears, most orthopaedists agree and focus their attention on a deeper analysis of the images. In this issue, we have a clear example with two very important, revolutionary papers. Yoo et al. [22] investigated the reliability of the muscle atrophy assessment by CYV view on MRI. Because of the possible tendon retraction, this quantification can be incorrect. This observation clearly explains why we see a "fake" regression of muscle hypotrophy after RCR. The other paper by Farshad-Amacker et al. [9], looking at partial supraspinatus tears, gives a possible explanation of functional cuff tears, thereby changing the indication scenario in this field. Another interesting study of MRI is that by Dwyer et al. [7]. It clearly states that a massive cuff tear retracted to or beyond the glenoid cannot be repaired anatomically and should be treated with a partial repair.

MRI is then frequently used to judge the outcome after $\mathrm{RC}$ repairs. Unfortunately, according to the study by Saccomanno et al. [17], MRI is only reliable when it comes to judging the structural integrity of the repaired cuffs as all the other possible criteria have not yet been validated.

Moving on to the surgical treatment of rotator cuff tears, we reach the core of this issue of the KSSTA on rotator cuff pathologies.

The first step in the treatment of rotator cuff dieaeses using the arthroscope is treating the impingement syndrome. Several studies, such as the one by Kappe et al. [12], included in this issue, confirm the value of subacromial decompression in patients with clinically evident subacromial impingement syndrome in the presence of positive impingement signs. When it comes to the arthroscopic RCR, Thès et al. [19] put together a clear and helpful "decisionmaking" paper that should be read by all orthopaedists and can simplify the indications for surgery. First, it recognises the concept of chronic and traumatic cuff tear, and then, in chronic cases suggests referring to the acromion-humeral distance (AHD) in order to select the appropriate indication.

Several papers in this issue analyse different kinds of RCR. Castagna et al. [5] demonstrates that in cases of partial cuff tear, trans-tendon repair has the same results as cuff take-down and full thickness repair. Another unresolved question in the field is the choice between tenotomy and tenodesis for the long head of the biceps during RCR. Zhang et al. [23] elegantly reports a randomized, controlled study in patients aged 55 and more, showing no difference between the two procedures, and thus suggesting tenotomy due to shorter surgery times and less pain for patients.

Another open question in arthroscopic RCR involves the choice between double-row and single-row repair. From a technical point of view, no animal [13] or clinical studies have clearly demonstrated any improvement in results using double-row repair, even if performed with a new kind of bridging techniques [4]. On the other hand, the cost analysis performed by Bisson et al. [2] shows that doublerow repair is not cost-effective, increasing costs by up to $\$ 260$ million a year. We, therefore, suggest that our contributors and readers should continue to explore this subject using new studies, especially RCTs, but adhere to using single-row repairs in their standard cases. Single-row repair should be still considered the "benchmark" in rotator cuff repair.

In massive irreparable cuff tears, we have two clear-cut arthroscopic repair strategies. In a prospective study [10], Franceschi et al. confirm that partial cuff repair produces better results than simple debridement and biceps tenotomy. Berdusco et al. [1] confirms that the interval slide technique gives satisfaction to more than $90 \%$ of partients and $45 \%$ have a healed cuff at MRI at the two-year follow-up.

The results of arthroscopic RCR are also investigated in this issue [8]. Complications of arthroscopic shoulder surgery are rare, but can be still serious [3, 11]. In any case, the overall results of arthroscopic RCR are favourable, with a clinical improvement in most cases. In a literature review of the long-term results, Spennacchio et al. [18] state that arthroscopic rotator cuff repair appears to be an effective, safe option for treating the symptoms of rotator cuff tears and produces successful clinical results that last over time, at a minimum follow-up of 5 years. Current evidence is insufficient to clearly define the relationship between the structural integrity of repaired cuffs and the long-term clinical outcome. At the final stage of massive irreparable cuff tears in elderly patients and in the case of cuff tear arthropathy, reverse shoulder arthroplasty has produced satisfactory results in large series of patients in the last few years.

Arthroscopy has thus become the gold standard for $\mathrm{RCR}$, due to its reduced invasiveness and fewer complications, but the results still include a large number of recurrences. The attempt to recreate a repair in the same fashion as open surgery is the postulated approach behind the double-row, transosseous-equivalent arthroscopic techniques or the most recent true transosseous arthroscopic repair that should improve results and reduce the high re-tear rate associated with this surgery.

Biology also represents an important environment for improving the quality of the repair and should be considered in order to improve the results [14].

For those focusing on this intriguing chapter of arthroscopy, a great deal has to be done in order to provide improved care for our patients. Enjoy this special issue of KSSTA Journal! 


\section{References}

1. Berdusco R, Trantalis JN, Nelson AA, Sohmer S, More KD, Wong B, Boorman RS, Lo IK (2013) Arthroscopic repair of massive, contracted, immobile tears using interval slides: clinical and MRI structural follow-up. Knee Surg Sports Traumatol Arthrosc. doi:10.1007/s00167-013-2683-9

2. Bisson L, Zivaljevic N, Sanders S, Pula D (2012) A cost analysis of single-row versus double-row and suture bridge rotator cuff repair methods. Knee Surg Sports Traumatol Arthrosc. doi:10.1007/s00167-012-2338-2

3. Bouliane M, Beaupre L, Ashworth N, Lambert R, Silveira A, Sheps DM (2013) Suprascapular nerve injury during arthroscopic superior labral repair: a prospective evaluation. Knee Surg Sports Traumatol Arthrosc. doi:10.1007/s00167-013-2415-1

4. Boyer P, Bouthors C, Delcourt T, Stewart O, Hamida F, Mylle G, Massin P (2013) Arthroscopic double-row cuff repair with suture-bridging: a structural and functional comparison of two techniques. Knee Surg Sports Traumatol Arthrosc. doi:10.1007/ s00167-013-2401-7

5. Castagna A, Borroni M, Garofalo R, Rose GD, Cesari E, Padua R, Conti M, Gumina S (2013) Deep partial rotator cuff tear transtendon repair or tear completion and repair? A randomized clinical trial. Knee Surg Sports Traumatol Arthrosc. doi:10.1007/ s00167-013-2536-6

6. Cho JH, Han KJ, Lee DH, Chung NS, Park DY (2013) Pit above the lesser tuberosity in axial view radiography. Knee Surg Sports Traumatol Arthrosc. doi:10.1007/s00167-013-2546-4

7. Dwyer T, Razmjou H, Henry P, Gosselin-Fournier S, Holtby R (2013) Association between pre-operative magnetic resonance imaging and reparability of large and massive rotator cuff tears. Knee Surg Sports Traumatol Arthrosc. doi:10.1007/ s00167-013-2745-z

8. Dwyer T, Razmjou H, Holtby R (2014) Full-thickness rotator cuff tears in patients younger than 55 years: clinical outcome of arthroscopic repair in comparison with older patients. Knee Surg Sports Traumatol Arthrosc. doi:10.1007/s00167-014-3094-2

9. Farshad-Amacker NA, Buck FM, Farshad M, Pfirrmann CW, Gerber C (2013) Partial supraspinatus tears are associated with tendon lengthening. Knee Surg Sports Traumatol Arthrosc. doi:10.1007/s00167-013-2475-2

10. Franceschi F, Papalia R, Vasta S, Leonardi F, Maffulli N, Denaro V (2012) Surgical management of irreparable rotator cuff tears. Knee Surg Sports Traumatol Arthrosc. doi:10.1007/ s00167-012-2317-7

11. Goto M, Gotoh M, Mitsui Y, Okawa T, Higuchi F, Nagata K (2013) Rapid collapse of the humeral head after arthroscopic rotator cuff repair. Knee Surg Sports Traumatol Arthrosc. doi:10.1007/s00167-013-2790-7

12. Kappe T, Knappe K, Elsharkawi M, Reichel H, Cakir B (2013) Predictive value of preoperative clinical examination for subacromial decompression in impingement syndrome. Knee Surg Sports Traumatol Arthrosc. doi:10.1007/s00167-013-2386-2

13. Liem D, Dedy NJ, Hauschild G, Gosheger G, Meier S, Balke M, Spiegel HU, Marquardt B (2014) In vivo blood flow after rotator cuff reconstruction in a sheep model: comparison of single versus double row. Knee Surg Sports Traumatol Arthrosc. doi:10.1007/ s00167-013-2429-8

14. Lorbach O, Baums MH, Kostuj T, Pauly S, Scheibel M, Carr A, Zargar N, Saccomanno MF, Milano G (2014) Advances in biology and mechanics of rotator cuff repair. Knee Surg Sports Traumatol Arthrosc. doi:10.1007/s00167-014-3487-2

15. Michener LA, Yesilyaprak SSS, Seitz AL, Timmons MK, Walsworth MK (2013) Supraspinatus tendon and subacromial space parameters measured on ultrasonographic imaging in subacromial impingement syndrome. Knee Surg Sports Traumatol Arthrosc. doi:10.1007/s00167-013-2542-8

16. Randelli P, Cucchi D, Ragone V, de Girolamo L, Cabitza P, Randelli M (2014) History of rotator cuff surgery. Knee Surg Sports Traumatol Arthrosc. doi:10.1007/s00167-014-3445-z

17. Saccomanno MF, Cazzato G, Fodale M, Sircana G, Milano G (2014) Magnetic resonance imaging criteria for the assessment of rotator cuff after repair: a systematic review and quality assessment of reliability studies. Knee Surg Sports Traumatol Arthrosc. doi:10.1007/s00167-014-3486-3

18. Spennacchio P, Banfi G, Cucchi D, D’ Ambrosi R, Cabitza P, Randelli P (2014) Long-term outcome after arthroscopic rotator cuff treatment. Knee Surg Sports Traumatol Arthrosc. doi:10.1007/ s00167-014-3234-8

19. Thès A, Hardy P, Bak K (2014) Decision-making in massive rotator cuff tear. Knee Surg Sports Traumatol Arthrosc. doi:10.1007/ s00167-014-3470-y

20. Tudisco C, Bisicchia S, Stefanini M, Antonicoli M, Masala S, Simonetti G (2013) Tendon quality in small unilateral supraspinatus tendon tears. Real-time sonoelastography correlates with clinical findings. Knee Surg Sports Traumatol Arthrosc. doi:10.1007/ s00167-013-2551-7

21. Wlk MV, Abdelkafy A, Hexel M, Krasny C, Aigner N, Meizer R, Landsiedl F (2014) Biomechanical evaluation of suture-tendon interface and tissue holding of three suture configurations in torn and degenerated versus intact human rotator cuffs. Knee Surg Sports Traumatol Arthrosc. doi:10.1007/s00167-014-2988-3

22. Yoo HJ, Choi JY, Hong SH, Kim EJ, Kim SH (2014) Quantifying rotator cuff atrophy and fatty degeneration at the supraspinatus origin in the scapular fossa. Knee Surg Sports Traumatol Arthrosc. doi:10.1007/s00167-014-2992-7

23. Zhang Q, Zhou J, Ge H, Cheng B (2013) Tenotomy or tenodesis for long head biceps lesions in shoulders with reparable rotator cuff tears: a prospective randomised trial. Knee Surg Sports Traumatol Arthrosc. doi:10.1007/s00167-013-2587-8 